\title{
Use of an oncology sperm bank: a Canadian experience
}

\author{
Amanda Selk, MD; ${ }^{*}$ Timea Belej-Rak, MD; ${ }^{\dagger}$ Heather Shapiro, MD, ${ }^{\ddagger}$ Ellen Greenblatt, $M D^{\ddagger}$
}

See related article on page 223

\section{Abstract}

Background: We performed a retrospective chart review in 2006 to review oncology patients' use of banked semen samples in fertility treatments at a tertiary care centre.

Methods: From 2002 to 2005, 367 oncology patients banked semen. During the same period, 31 patients used banked samples in 48 treatment cycles. Samples were used for intrauterine insemination (IUI) in 28 cycles and for in vitro fertilization (IVF) with or without intracytoplasmic sperm injection (ICSI) in 20 cycles. Results: Pregnancy rates per cycle were $21 \%$ for IUI and $50 \%$ for IVF with or without ICSI. Overall, 16 of the 31 couples achieved a pregnancy with assisted reproductive technologies (52\%).

Conclusion: This data indicates high pregnancy success rates with the use of banked semen samples from men with cancer.

Can Urol Assoc J 2009;3(3):219-22

\section{Résumé}

Contexte : Une revue rétrospective de dossiers a été effectuée afin d'examiner le recours à des échantillons de sperme provenant de patients cancéreux pour le traitement de l'infertilité dans un centre de soins tertiaires.

Méthodes : Entre 2002 et 2005, des échantillons de sperme provenant d'un total de 367 patients atteints de cancer ont été mis en banque. Durant la même période, 31 patientes ont utilisé ces échantillons au cours de 48 cycles de traitement. Les échantillons ont été utilisés pour insémination intra-utérine (IIU) lors de 28 cycles et pour fertilisation in vitro (FIV) avec ou sans injection intracytoplasmique de sperme (ICSI) lors de 20 cycles.

Résultats : Le taux de grossesse par cycle était de $21 \%$ avec I'IIU et de $50 \%$ pour la FIV avec ou sans ICSI. Au total, 16 des 31 patientes sont devenues enceintes (52\%).

Conclusion : Ces données montrent des taux élevés de grossesse obtenus par l'utilisation d'échantillons de sperme provenant $d^{\prime}$ hommes atteints de cancer.

\section{Introduction}

About 10000 Canadians between the ages of 20 and 44 are diagnosed with cancer every year, and there are about
150000 young cancer survivors living in Canada. ${ }^{1}$ Infertility is a well-documented side effect of cancer treatment as both chemotherapy and radiotherapy can impair spermatogenesis. ${ }^{2}$ Sperm banking is the only proven fertility preservation method available to men facing potentially gonadotoxic cancer therapies. Unfortunately, few men are offered banking by their physicians. ${ }^{3,4}$ In addition, there are few published studies about outcomes of the use of banked oncology cryopreserved semen and advanced reproductive technologies. We performed this study to review the use of a sperm cryobank by oncology patients and the subsequent application of cryopreserved samples for fertility treatments.

\section{Methods}

After receiving research ethics board approval, we conducted a retrospective chart review of 2 separate patient groups. The first group of patients banked semen samples between 2002 and 2005. The second group included all patients who used banked samples for assisted reproductive technologies (ART) between 2002 and 2005. These patients banked samples anytime from 1984 to 2005 . The 2 groups were analyzed separately. Research was conducted through the Mount Sinai Hospital Oncology Sperm Bank, an academic fertility centre associated with the University of Toronto. Data was collected in 2006 and subsequently analyzed. Patients that transferred samples for use at other fertility centres were not included in our analysis because of limited follow-up data.

\section{Results}

From 2002 to 2005, a total of 388 patients were referred to the bank. Of these, 21 were unable to bank: 19 were azoospermic, 1 was unable to produce a sample and 1 had very poor sample quality and chose not to bank. Of the azoospermic patients, 4 had already received chemotherapy and 1 had a testicle removed before banking. These samples were all discarded. The remaining 367 patients banked semen samples. The most common diagnoses were 
testicular cancer (29.9\%) and Hodgkin lymphoma (14.7\%) (Table 1).

Prefreeze and post-thaw semen analysis were performed on each sample at the time of cryopreservation. Post-thaw analysis is recommended at the time of banking to give patients more accurate information about their chances of conception with ART so they can appropriately decide whether to proceed with intrauterine insemination (IUI) versus in vitro fertilization (IVF), with or without intracytoplasmic sperm injection (ICSI). Not all sperm survives the freeze-thaw process with good motility. Semen concentration rates were lowest in patients with testicular cancer and Hodgkin lymphoma compared with patients with other cancers (Table $\left.2^{5}\right)$.

Overall, of the 367 who chose to bank their samples, $0.6 \%$ exhibited azoosperia, $29.7 \%$ oligospermia and $69.7 \%$ banked at least 1 sample that was normospermic. As many patients banked multiple samples, $24.2 \%$ of patients produced some samples that were oligospermic and others that were normospermic.

Between 2002 and 2005, 31 patients used banked samples in 48 cycles of treatment at Mount Sinai Hospital. Semen samples that were used had been banked as far back as 1984 .

The diagnoses of these patients were most commonly testicular cancer (8 patients) and Hodgkin lymphoma

$\begin{aligned} & \text { Table 1. Demographics by cancer type of patients } \\
& \text { who banked semen samples }\end{aligned}$
\begin{tabular}{lccc} 
& \multicolumn{4}{l}{$\begin{array}{c}\text { Hodgkin } \\
\text { Demographic }\end{array}$} & Testicular & $\begin{array}{c}\text { lymphoma } \\
\text { Other }\end{array}$ \\
\hline No. (\%) of patients & $110(29.2)$ & $54(14.7)$ & $203(55.3)$ \\
Mean age at diagnosis, yr & 27 & 22 & 28 \\
$\%$ with partner & 38 & 33 & 42 \\
$\%$ with children & 4 & 4 & 14 \\
\hline
\end{tabular}

Table 2. Prefreeze and post-thaw semen analysis parameters by cancer type in patients who banked semen samples*

\begin{tabular}{|c|c|c|c|}
\hline Parameter† & Testicular & $\begin{array}{l}\text { Hodgkin } \\
\text { lymphoma }\end{array}$ & Other \\
\hline $\begin{array}{l}\text { Prefreeze concentration, } \\
\text { million/mL }\end{array}$ & 13.35 & 31.98 & 38.50 \\
\hline $\begin{array}{l}\text { Post-thaw concentration, } \\
\text { million/mL }\end{array}$ & 8.25 & 13.95 & 20.05 \\
\hline Prefreeze motility, \% & 52 & 45 & 49 \\
\hline Post-thaw motility, \% & 29 & 27 & 27 \\
\hline $\begin{array}{l}\text { Prefreeze normal } \\
\text { morphology, \% }\end{array}$ & 29 & 24 & 27 \\
\hline
\end{tabular}

(6 patients). The other patients had a variety of cancer diagnoses including non-Hodgkin lymphoma, Ewing sarcoma, acute myeloid leukemia, and lung, brain, thyroid, colon and prostate cancers.

Of the 31 patients who accessed samples for ART, the mean time from banking samples to use was 52 (range 0-227) months. Samples were used for IUI in 28 cycles and for IVF with or without ICSI in 20 cycles. The range of attempts was 1-6 cycles (mean no. of IUI cycles/patient was 1.4 and mean no. of IVF/ICSI cycles/patient was 0.95). Pregnancy rates per cycle were $21 \%$ for IUI and $50 \%$ for IVF with or without ICSI. Overall, 16 of the 31 couples achieved a pregnancy with ART. Interestingly, 1 additional patient achieved a pregnancy without ART after an IUI failed. For analysis, this spontaneous pregnancy was included in the "no pregnancy" group as it was not achieved with ART. Only 1 patient used all their banked samples for fertility treatments without success (Table 3 ).

Semen concentration rates were again lowest in patients with testicular cancer and Hodgkin lymphoma compared with patients with other cancers (Table 4).

Patients who achieved a pregnancy with ART had both significantly higher post-thaw semen concentrations and post-thaw motilities compared with those patients who did not achieve a pregnancy.

Overall, 19 of the 367 patients (5.2\%) who banked between 2002 and 2005, accessed their samples during the same period.

\section{Discussion}

Our data indicate high pregnancy success rates with the use of banked semen samples from men with cancer. These rates are equal to or better than those reported in all patients using ART. ${ }^{6,7}$ The only other Canadian series published in

\begin{tabular}{|c|c|c|c|}
\hline Parameter & $\begin{array}{l}\text { Testicular, } \\
\quad n=8\end{array}$ & $\begin{array}{c}\text { Hodgkin } \\
\text { Iymphoma, } \\
n=6\end{array}$ & $\begin{array}{l}\text { Other, } \\
n=17\end{array}$ \\
\hline $\begin{array}{l}\text { Prefreeze concentration, } \\
\text { million/mL }\end{array}$ & 6.30 & 25.60 & 42.38 \\
\hline $\begin{array}{l}\text { Post-thaw concentration, } \\
\text { million/mL }\end{array}$ & 4.45 & 8.05 & 17.20 \\
\hline Prefreeze motility, \% & 33 & 38 & 59 \\
\hline Post-thaw motility, \% & 28 & 31 & 37 \\
\hline $\begin{array}{l}\text { Prefreeze normal } \\
\text { morphology, \% }\end{array}$ & 40 & 53 & 40 \\
\hline
\end{tabular}


this area had fewer patients but had similar ART success rates. ${ }^{4}$ It is crucial that oncology patients be informed of these encouraging results.

In our centre, patients are usually referred to bank semen before receiving any oncology treatments and therefore treatment was unlikely to have a major effect on semen parameters in this study. However, when azoospermic patients were referred to bank semen it was found that 5 of 21 patients $(24 \%)$ were treated with chemotherapy or surgery before banking, thus illustrating the gonadotoxic effects of treatment. Previous authors have reported impaired spermatogenesis in cancer patients even before the start of treatments, especially in patients with testicular cancer, Hodgkin lymphoma and leukemias. ${ }^{8-11}$ It may be that the disease process has an effect on spermatogenesis though the exact mechanism is not well understood.

This study is limited by its observational and retrospective nature; however, it adds to the literature as patient numbers are relatively large compared with all previously published studies. ${ }^{12-17}$ As ART continues to improve, success rates from older studies are not helpful in counselling patients. Patients need up-to-date numbers in order to make informed choices.

Research in this area is difficult and time-consuming because young cancer patients often do not access their samples for many years after they have banked their sperm, when fertility becomes important to them. During 4 years, $5.2 \%$ of patients returned to use their samples. In other published series less than $10 \%$ of patients ever returned to use frozen spermatozoa for fertility treatments. ${ }^{16}$ Fertility treatments for men are not covered by provincial insurance

\begin{tabular}{|c|c|c|c|}
\hline \multirow[b]{2}{*}{ Parameter } & \multicolumn{2}{|c|}{ No. of patients } & \multirow[b]{2}{*}{$p$ value } \\
\hline & No pregnancy & Pregnancy & \\
\hline Hodgkin lymphoma & 2 & 3 & \\
\hline Testicular cancer & 5 & 3 & \\
\hline Other cancer & 8 & 9 & \\
\hline $\begin{array}{l}\text { Prefreeze concentration, } \\
\text { million/mL }\end{array}$ & 21.20 & 27.99 & 0.22 \\
\hline $\begin{array}{l}\text { Post-thaw concentration, } \\
\text { million/mL }\end{array}$ & 5.88 & 15.95 & 0.014 \\
\hline Prefreeze motility, \% & 49 & 53 & 0.28 \\
\hline Post-thaw motility, \% & 27 & 38 & $<0.001$ \\
\hline $\begin{array}{l}\text { Prefreeze normal } \\
\text { morphology, \% }\end{array}$ & 30 & 50 & 0.09 \\
\hline
\end{tabular}

plans, and it is unclear whether financial constraints are a cause of low access rates. Fortunately, oncology semen samples show good function after many years of freezing. ${ }^{18}$ Furthermore, when oncology samples have been used in ART there have been no reported increases in congenital abnormalities. ${ }^{19,20}$

Between $15 \%$ and $30 \%$ of young male cancer survivors never regain their fertility after treatment. ${ }^{21}$ There are many risk factors that affect fertility and there is little data to help counsel an individual patient about his own specific risk of infertility or sterility. ${ }^{22}$ Until improved prediction tools become available, the option of cryobanking sperm for fertility preservation should be discussed with all sexually mature men before they receive potentially gonadotoxic cancer therapies. Oncologists, urologists, internists and family doctors all interact with young male cancer patients and should refer them to sperm banking facilities before the start of treatment.

From the *Department of Obstetrics and Gynaecology, University of Toronto, Toronto, Ont., †lifeQuest Centre for Reproductive Medicine, Toronto, Ont., the ‡Department of Obstetrics and Gynaecology, University of Toronto and Mount Sinai Hospital, Toronto, Ont.

This article has been peer reviewed.

Competing interests: None declared.

\section{References}

1. Cancer care Ontario: cancer in young adults in Canada, Toronto, Canada, 2006. Available: www .phac-aspc.gc.ca/publicat/cyac-cjac06/index-eng.php (accessed 2009 Apr 30).

2. Meistrich ML Effects of chemotherapy and radiotherapy on spermatogenesis. Eur Urol 1993;23:136-41.

3. Schover LR, Brey K, Lichtin A, et al. Oncologists' attitudes and practices regarding banking sperm before cancer treatment. J Clin Oncol 2002;20:1890-7.

4. Neal MS, Nagel K, Duckworth J, et al. Effectiveness of sperm banking in adolescents and young adults with cancer: a regional experience. Cancer 2007;110:1125-9.

5. World Health Organization. WHO laboratory manual for the examination of human semen and spermcerival mucus interaction. 4th ed., Cambridge (UK): Cambridge University Press; 1999.

6. Gunby J, Daya S. Assisted reproductive technologies (ART) in Canada: 2003 results from the Canadian ART Register. Fertil Steril 2007;88:550-9.

7. Canadian Fertility and Andrology Society. Live birth rates. Available: www.cfasonline.ca/index.php?option $=$ com_content\&view=article\&id=260\&ltemid=460 (accessed 2009 Apr 30).

8. Agarwal A, Allamaneni SS. Disruption of spermatogenesis by the cancer disease process. J Natl Cancer Inst Monogr 2005;(34):9-12.

9. Chung K, Irani J, Knee G, et al. Sperm cryopreservation for male patients with cancer: an epidemiological analysis at the University of Pennsylvania. Eur J Obstet Gynecol Reprod Biol 2004;113(Suppl 1): S7-11.

10. Hallak J, Kolettis PN, Sekhon VS, et al. Sperm cryopreservation in patients with testicular cancer. Urology 1999:54:894-9.

11. Hallak J, Kolettis PN, Sekhon VS, et al. Cryopreservation of sperm from patients with leukemia: Is it worth the effort? Cancer 1999;85:1973-8.

12. Agarwal $A$, Ranganathan $P$, Kattal $N$, et al. Fertility after cancer: a prospective review of assisted reproductive outcome with banked semen specimens. Fertil Steril 2004;81:342-8.

13. Kelleher S, Wishart SM, Liu PY, et al. Long-term outcomes of elective human sperm cryostorage. Hum Reprod 2001;16:2632-9.

14. Lass A, Akagbosu F, Brinsden P. Sperm banking and assisted reproduction treatment for couples following cancer treatment of the male partner. Hum Reprod Update 2001;7:370-7. 
Selk at al.

15. Meseguer $M$, Molina N, Garcia-Valasco JA, et al. Sperm cryopreservation in oncological patients: a 14-year follow-up study. Fertil Steril 2006;85:640-5.

16. Ragni G, Somigliana E, Restelli L, et al. Sperm banking and rate of assisted reproduction treatment: insights from a 15-year cryopreservation program for male cancer patients. Cancer 2003;97:1624-9.

17. van Casteren NJ, van Santbrink EJ, van Inzen W, et al. Use rate and assisted reproduction technologies outcome of cryopreserved semen from 629 cancer patients. Fertil Steril 2008;90:2245-50.

18. Clarke GN, Liu de Y, Baker HW. Recovery of human sperm motility and ability to interact with the human zona pellucida after more than 28 years of storage in liquid nitrogen. Fertil Steril 2006;86:721-2.

19. Lass A, Akagbosuu F, Abusheikha N, et al. A programme of semen cryopreservation for patients with malignant disease in a tertiary infertility centre: lessons from 8 years' experience. Hum Reprod 1998; 13:3256-61.
20. Hallak J, Hendin BN, Thomas AJ Jr, et al. Investigation of fertilizing capacity of cryopreserved spermatozoa from patients with cancer. J Urol 1998;159:1217-20.

21. Tournaye H, Goossens J, Verheyen G, et al. Preserving the reproductive potential of men and boys with cancer: current concepts and future prospects. Hum Reprod Update 2004;10:525-32.

22. Lee SJ, Schover LR, Partridge AH, et al. American Society of Clinical Oncology recommendations on fertility preservation in cancer patients. J Clin Oncol 2006;24:2917-31.

Correspondence: Dr. Amanda Selk, Department of Obstetrics and Gynaecology, University of Toronto, 92 College St., Toronto ON M5G 1L4; amanda.selk@utoronto.co

\section{Change of address}

We require 6 to 8 weeks' notice to ensure uninterrupted service. Please send your current mailing label, new address and the effective date of change to:

\section{CUAJ}

1155 University Ave., Suite 1303

Montréal QC H3B 3A7

fax 514 395-1664

journal@cua.org 